neutrons scattered in lead do not enhance the 140 sec. isotope. It seems probable that the inelastic collisions of fast neutrons are relatively frequent in many elements. Fleischmann ${ }^{3}$ has found that $\gamma$-rays are produced not only by 'slow' but also by 'primary' neutrons in copper, iron, cadmium and lead. We may assume that the same effect takes place also in silicon, zinc, silver, tin and mercury.

TABLE 1.

\begin{tabular}{|c|c|c|c|c|c|c|c|c|c|c|c|}
\hline Scatterer & $\mathrm{C}$ & $\mathrm{Al}$ & $\mathrm{Si}$ & $\mathrm{Fe}$ & $\mathrm{Cu}$ & $\mathrm{Zn}$ & $\mathrm{Ag}$ & $\mathrm{Cd}$ & $\mathrm{Sn}$ & $\mathrm{Hg}$ & $\mathrm{Pb}$ \\
\hline $\begin{array}{c}\text { Thickness of } \\
\text { scatterer } \\
\text { (gm./cm. }\end{array}$ & $1 \cdot 33$ & $2 \cdot 25$ & $1 \cdot 27$ & $6 \cdot 72$ & $7 \cdot 75$ & $6 \cdot 21$ & $9 \cdot 10$ & $7 \cdot 39$ & $6 \cdot 37$ & $10 \cdot 06$ & $9 \cdot 78$ \\
\hline $\begin{array}{c}\text { Percentage in- } \\
\text { crease of 22 } \\
\text { sec. product }\end{array}$ & 32 & 32 & 2 & 0 & 28 & 2 & -5 & 17 & 20 & -10 & 3 \\
\hline $\begin{array}{c}\text { Percentage in- } \\
\text { crease of 140 } \\
\text { sec. product }\end{array}$ & 1 & -7 & 7 & 9 & 14 & 14 & 12 & 9 & 6 & 8 & 9 \\
\hline
\end{tabular}

The 22 sec. product is strongly enhanced by neutrons scattered in carbon, aluminium, copper and tin. and its quantity is diminished in the case of silver and mercury. The different behaviour of this isotope may be related to the selective absorption of silver for neutrons producing the 22 sec. activity ${ }^{4}$. We have found that if a silver foil $0.05 \mathrm{~mm}$. thick or a sheet of boron of $0.036 \mathrm{gm} . / \mathrm{cm}^{2}$ is placed between the copper scatterer and the silver receiver, then there is no increase of the short period product. This shows that neutrons scattered in copper are strongly absorbed in silver and in boron. The scattering in silver and mercury is interesting in showing also that primary neutrons responsible for the $22 \mathrm{sec}$. products are strongly absorbed in some elements.

The facts are complicated, and it seems that in addition to the inelastic collisions connected with the emission of $\gamma$-rays, some other mechanisms may also be involved.

J. Rotblat.

M. ZYW.

Mirosiaw Kernbaum Radiological Laboratory, Warsaw Society of Sciences. Dec. 31.

${ }^{1}$ NATURE, 134, 970 (1934).

2 NATURE, 136, 870 (1935).

4 Amaldi and Fermi, Ric. Sci., 6, Nr. 11-12. Szilard, NATURE A Amalu

\section{Energy of $\gamma$-Rays excited by Slow Neutrons}

IN a previous letter [NATURE, Jan. 4, p. 30] we have reported briefly the result of experiments determining the mean cross-section for the recombination of the proton with a 'slow neutron' to form a deuteron. As the continuation of it, we have recently measured the energy of a quantum of $\gamma$-rays accompanying the above process, by determining the maximum energy of the secondary electron by the usual method of coincidence of two counters. The result is shown in Fig. 1, together with the results of similar measurements on other $\gamma$-rays. The abscissa indicates the thickness of the aluminium absorber inserted between the two counters.

We see that the number of simultaneous discharges (less the number of accidental coincidences) falls to zero fairly abruptly at the absorber thickness of $2.8 \mathrm{~mm}$. As the wall of the counter was made of aluminium plate of $0.1 \mathrm{~mm}$. in thickness, we obtain $3.0 \mathrm{~mm}$. for the maximum range in aluminium of a secondary electron ejected by the $\gamma$-rays. According

to Varder $^{1}$ and Madgwick ${ }^{2}$, this corresponds to an electron of $2.0 \times 10^{6}$ e.v. energy, which, in its turn, gives the energy of a quantum of $\gamma$-rays as $2.2 \times 10^{6}$ e.v. This value agrees quite well with the value $2 \cdot 1 \times 10^{6} \mathrm{e}$.v. obtained by Chadwick and Goldhaber ${ }^{3}$ for the energy of dissociation of a deuteron into a proton and a neutron, but does not agree with the value of Fleischmann ${ }^{4}, 1.5 \times 10^{6}$ e.v. obtained from the measurement on the absorption of $\gamma$-rays.

We have also measured the energy of $\gamma$-rays excited in eadmium, chlorine, copper and iron by slow neutrons. It is interest. ing to note that $\gamma$-rays from cadmium have at least two components. The energy of the softer component is about $2 \times 10^{6}$ e.v., while that of the harder one seems to be of the order of $1.0 \times 10^{7}$ e.v., though we could not determine the maximum range of the secondary electron accurately. In the case of chlorine, the $\gamma$-rays seem to be homogeneous and the energy of a quantum corresponds to $5.0 \times 10^{6}$ e.v. In the case of iron and copper, we have again observed secondary particles of high energy comparable with those pro duced with cadmium. These components of high energy may correspond to those observed by Joliot and Kowarski ${ }^{5}$. Lately, Rasetti ${ }^{6}$ has reported the

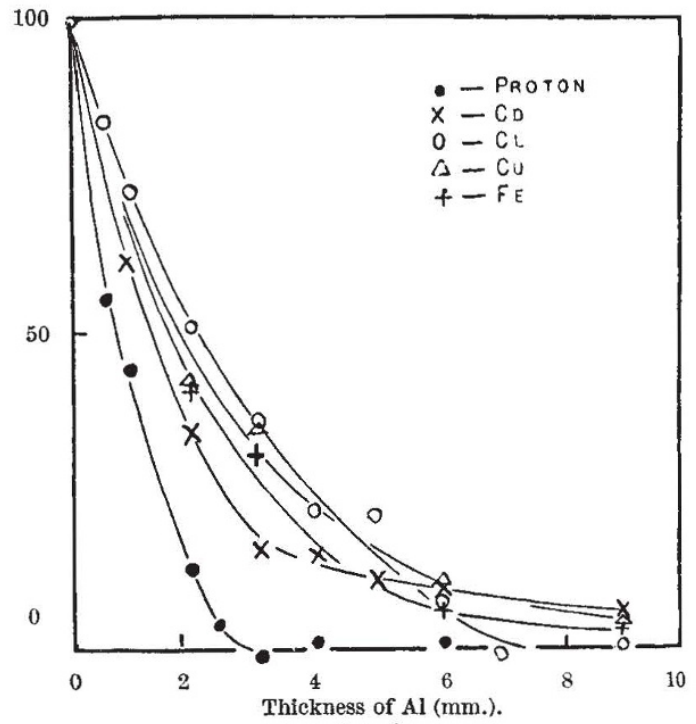

FIG. 1.

results of experiments very similar to those described here. The elements examined by both Rasetti and ourselves are cadmium and chlorine. As to cadmium, it seems that he has overlooked the presence of the harder component, while in the case of chlorine, our value is somewhat lower than that given by him.

A fuller account of the investigation will appear shortly in Proc. Phys.-Math. Soc. Jap.

Physical Institute,

Osaka Imperial University. Nov, 24.

1 Varder, Phil. Mag., 29, 726 (1915).

2 Madgwick, Proc. Camb. Phil. Soc., 23, 970 (1927).

${ }^{3}$ Chadwick and Goldhaber, Proc. Roy. Soc., 151, 479 (1935).

4 Fleischmann, Z. Phys., 91, 242 (1935)

Joliot and Kowarski, C.R., 200, 824 (1935)

- Rasetti, Z. Phys., 97, 64 (1935). 